\title{
Short-term hearing results in adults after a stapedotomy
}

\author{
NADER SAKI ${ }^{1, A}$, B, MARYAM KARDONI 1, D, E, MEHDI KARIMI 2, A, C-E,
} ORCID ID: 0000-0003-4564-6406 AMIR MOHAMMAD EGHBALNEJAD MOFRAD2, E, F

${ }^{1}$ Hearing Research Center, Ahvaz Jundishapur University of Medical Sciences, Ahvaz, Iran

${ }^{2}$ Student Research Committee, Ahvaz Jundishapur University of Medical Sciences, Ahvaz, Iran

A - Study Design, B - Data Collection, C - Statistical Analysis, D - Data Interpretation, E - Manuscript Preparation, F - Literature Search, $\mathbf{G}$ - Funds Collection

Summary Background. A stapedectomy or stapedotomy is known as the best treatment option for patients with otosclerosis. Otosclerosis is a primary disease of the bony labyrinth capsule, which is characterized by one or more localized foci, where bone deposition occurs repeatedly. The best and most effective treatment option is a stapedectomy or stapedotomy.

Objectives. The present study evaluated the short-term hearing results in patients with otosclerosis after primary stapes surgery. Material and methods. In this retrospective study, the short-term hearing results of all patients with otosclerosis after a primary stapedotomy admitted to the Ahvaz Emam hospital from 2007 to 2017 was evaluated. Improvement in hearing was evaluated according to the pre- and post-audiometry results. Air Conduction (AC), Bone Conduction (BC) and Air-Bone Gap (ABG) thresholds were recorded at 500, 1000,2000 and $4000 \mathrm{~Hz}$. SPSS software (Version 22.0) was used for statistical analysis.

Results. Of the 413 cases, 231 (55.93\%) and 182 (44.07\%) were females and males, respectively. The mean age of patients was 39.06 \pm 11.29 years. The disease in $131(31.72 \%)$ was bilateral. The mean ABG in 341 patients $(82.63 \%) \leq 10 \mathrm{~dB}$ and in 52 patients (12.47\%) was $10-20 \mathrm{~dB}$.

Conclusions. The results of the study showed that a primary stapedotomy is a successful and effective way to improve short-term hearing results in adults with otosclerosis.

Key words: hearing loss, otosclerosis, audiometry, stapedotomy.

Saki N, Kardoni M, Karimi M, Eghbalnejad Mofrad AM. Short-term hearing results in adults after a stapedotomy. Fam Med Prim Care Rev 2019; 21(2): 144-148, doi: https://doi.org/10.5114/fmpcr.2018.79991.

\section{Background}

Otosclerosis is a primary disease of the bony labyrinth capsule [1], which is characterized by one or more localized foci, where bone deposition occurs repeatedly. These foci may gradually invade the annular ligament and stapes bone and lead to bone ankylosis and reduce or eliminate sound conduction [2]. Otosclerosis is a common cause of hearing loss in 15-50 year old patients [3] and is bilateral in most cases (60\%) [4]. Otosclerosis is a rare clinical disease, which affected $0.5-2 \%$ of the world's population. This disease is limited to the otic capsules and causse progressive conductive hearing loss, as well as mixed hearing loss, sensorineural hearing loss and vestibular disorders [3]. However, the etiological and pathological mechanism of the disease is not clear. Researcher believed that otosclerosis is a hereditary illness transmitted as an autosomal dominant with incomplete penetrance and a variable expression pattern $[5,6]$.

One of the main clinical findings in otosclerosis is progressive conductive hearing loss, especially at low frequencis (200$-500 \mathrm{~Hz}$ ), which is sometimes accompanied by sensorineural hearing loss. Tinnitus is another common symptom of the disease [4-7]. Otosclerosis plaque is mostly (80-95\%) found in the anterior part of the oval window and causes footplate fixation and hearing loss [6].

The best and most effective treatment option is a stapedectomy or stapedotomy $[2,8]$. In the case of hearing loss with more than $30 \mathrm{~dB}$ and a rinne value, surgery is the only treatment option $[9,10]$.

Stapes surgery includes total or partial replacement of the upper part of fixed stapes, named stapedectomy and stapedotomy, respectively [11].

Previous studies reported the improvement of hearing in patients with otosclerosis after a primary stapedectomy [1013]. However, adverse hearing results have been observed in some patients, especially in patients with an advanced form of the disease [3]. A delay in treatment may also lead to progression of otosclerosis and permanent deafness. Therefore, the disease must be diagnosed at an early stage, and a stapedotomy or stapedectomy must be performed as a selective treatment for improvement of hearing [4].

\section{Objectives}

The present study was designed to evaluate the results of hearing improvement after a stapedotomy in adult patients with otosclerosis and to evaluate the effect of some variables in post-surgical hearing results.

\section{Material and methods}

\section{Study design}

This is a descriptive study conducted on patients with otosclerosis under surgical treatment at the Ahvaz Imam Khomeini Hospital from 2007-2017. For this purpose, after permission was granted by the Ethics Committee of Ahvaz Jundishapur University of Medical Sciences (Ethics code: IR.AJUMS.REC.1396.1051). 


\section{Setting, participants and variables}

Sampling was done by census method, and inclusion criteria included all patients between $18-70$ years of age with a clinical diagnosis of otosclerosis undergoing stapedotomy surgery for the first time. According to these criteria, the sample size was 542 patients. Patients with repeated surgery and incomplete files were excluded from the study. Eventually, pre- and post-operative audiograms were available for 413 patients.

In this study, stapedotomy surgery was performed on patients with a teflon piston prosthesis by the same surgeon (first author). Epidemiologic and clinical data included: age, gender, unilateral or bilateral involvement and a pre- and post-operative audiogram collected and recorded in the designed form.

\section{Pure Tone Audiometry (PTA) evaluation}

Improvement in hearing was evaluated according to the pre- and post-audiometry results. PTA factors include Air Conduction (AC), Bone Conduction (BC) and Air-Bone Gap (ABG), at frequencies of $500,1000,2000$ and $4000 \mathrm{~Hz}$ were evaluated before and after surgery (last follow-up session, at least 6 weeks after surgery). Air-Bone Gap (ABG) was calculated as BC before surgery and $A C$ threshold after surgery. The values expressed in $\mathrm{dB}$ were recorded for the mentioned frequencies. Hearing loss in the mentioned frequencies was evaluated in five groups: ABG below $10 \mathrm{~dB}$ (excellent outcome), 10-20 dB (acceptable outcome), 20-30 dB (weak outcome), above $30 \mathrm{~dB}$ (very weak outcome) and complete deafness (bad outcome).

\section{Statistical analysis}

SPSS software (Version 22.0) was used for statistical analysis. Descriptive statistics including mean, standard deviation, frequency and percentage of frequency were analyzed. Kolmogorov-Smirnov and Leven tests were used for normality and variance homogeneity tests, respectively. To measure the significance of differences and compare quantitative and qualitative variables, the $t$-test and chi-squared test were used, respectively. The paired $t$-test was used before and after surgery results. The significance level in the tests was considered to be 0.05 .

\section{Results}

\section{Descriptive data}

In the present study, 231 (55.93\%) of the patients were female, and $182(44.07 \%)$ of the patients were male. All participants were $18-67$ years of age (mean age $39.06 \pm 11.29$ ).

Most of the patients $(n=197 ; 47.70)$ were in the $31-40$ age group (Figure 1). The disease in 282 patients $(68.28 \%$ ) was unilateral, and in 131 (31.72), it was bilateral. Surgery was performed on the right ear in $249(60.29 \%)$ and on the left ear in 164 (39.71\%) cases. The mean follow-up time after surgery was 3.27 months (range 2-7 months).

In all of the mentioned frequencies, the pre- and post-surgery AC measurement was significantly different $(p<0.05)$, and the highest difference before and after surgery was observed in low frequencies (500 and $1000 \mathrm{~Hz}$ ) (Table 1).

\section{Outcome data and main results}

In all frequencies except $4000 \mathrm{~Hz}$, the before and after BC measurement was significantly decreased $(p<0.05)$. The highest difference before and after surgery was observed at 2000 $\mathrm{Hz}$. The BC pre- and post-surgery measurement at $4000 \mathrm{~Hz}$ was not significantly different (Table 2).

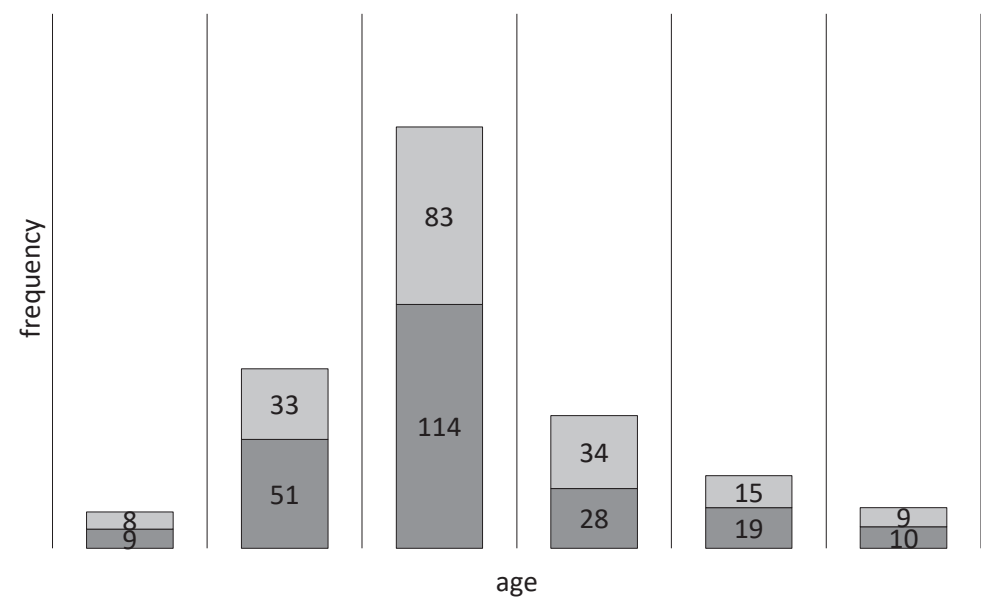

Figure 1. Frequency distribution of patients in different age groups by gender

\begin{tabular}{|l|l|l|l|l|}
\hline \multicolumn{6}{|l|}{ Table 1. Average threshold of Air Conduction (AC) before and after surgery } \\
\hline$p$ & Difference & After surgery (dB) & Before surgery (dB) & PTA \\
\hline 0.0001 & $31.70 \pm 12.17$ & $19.89 \pm 12.61$ & $51.60 \pm 14.03$ & Hertz 500 \\
\hline 0.0001 & $33.72 \pm 12.74$ & $20.64 \pm 12.31$ & $54.36 \pm 13.57$ & Hertz 1000 \\
\hline 0.0001 & $28.29 \pm 13.52$ & $22.66 \pm 12.07$ & $50.96 \pm 16.76$ & Hertz 2000 \\
\hline 0.0001 & $25.85 \pm 18.92$ & $28.30 \pm 15.64$ & $54.15 \pm 19.03$ & Hertz 4000 \\
\hline
\end{tabular}

\begin{tabular}{|l|l|l|l|l|}
\hline \multicolumn{6}{|l|}{ Table 2. Average threshold of Bone Conduction (BC) before and after surgery } \\
\hline P-value & Difference & After surgery (dB) & Before surgery (dB) & PTA \\
\hline 0.0001 & $5.00 \pm 8.40$ & $15.64 \pm 8.69$ & $20.64 \pm 10.40$ & Hertz 500 \\
\hline 0.0001 & $9.04 \pm 10.45$ & $17.23 \pm 10.97$ & $26.28 \pm 11.72$ & Hertz 1000 \\
\hline 0.0001 & $13.29 \pm 12.38$ & $19.68 \pm 9.85$ & $32.98 \pm 13.81$ & Hertz 2000 \\
\hline 0.084 & $4.14 \pm 16.12$ & $24.68 \pm 13.20$ & $28.83 \pm 15.88$ & Hertz 4000 \\
\hline
\end{tabular}




\begin{tabular}{|l|l|l|l|l|}
\hline \multicolumn{5}{|l|}{ Table 3. Average Air-Bone Gap (ABG) before and after surgery } \\
\hline $\boldsymbol{p}$ & Difference & Before surgery (dB) & After surgery (dB) & PTA \\
\hline 0.0001 & $27.23 \pm 10.77$ & $4.03 \pm 6.39$ & $31.28 \pm 10.07$ & Hertz 500 \\
\hline 0.0001 & $24.36 \pm 12.23$ & $3.94 \pm 6.42$ & $28.30 \pm 11.24$ & Hertz 1000 \\
\hline 0.0001 & $17.02 \pm 12.18$ & $2.98 \pm 4.50$ & $20.00 \pm 11.37$ & Hertz 2000 \\
\hline 0.0001 & $21.91 \pm 13.81$ & $4.15 \pm 7.96$ & $26.06 \pm 12.85$ & Hertz 4000 \\
\hline
\end{tabular}

\begin{tabular}{|l|l|l|l|l|l|}
\hline \multicolumn{6}{|l|}{ Table 4. Improvement of Air-Bone Gap (ABG) after surgery } \\
\hline Total & Hertz 4000 & Hertz 2000 & Hertz 1000 & Hertz 500 & ABG result \\
\hline$(82.63) 341$ & $(81.36) 336$ & $(84.75) 350$ & $(82.57) 341$ & $(81.84) 338$ & $\begin{array}{l}0-10 \mathrm{~dB} \\
\text { excellent outcome }\end{array}$ \\
\hline$(12.47) 52$ & $(13.08) 54$ & $(11.38) 47$ & $(12.59) 52$ & $(12.83) 53$ & $\begin{array}{l}11-20 \mathrm{~dB} \\
\text { acceptable outcome }\end{array}$ \\
\hline$(2.72) 11$ & $(3.15) 13$ & $(1.94) 8$ & $(2.66) 11$ & $(3.15) 13$ & $\begin{array}{l}\text { 21-30 dB } \\
\text { weak outcome }\end{array}$ \\
\hline$(1.45) 6$ & $(1.69) 7$ & $(1.21) 5$ & $(1.45) 6$ & $(1.54) 6$ & very weak outcome \\
\hline$(0.73) 3$ & $(0.73) 3$ & $(0.73) 3$ & $(0.73) 3$ & $(0.73) 3$ & $\begin{array}{l}\text { complete deafness } \\
\text { bad outcome }\end{array}$ \\
\hline
\end{tabular}

The difference between pre- and post-surgery ABG was significant $(p<0.05)$, and the highest difference before and after surgery was observed at low frequencies (500 and $1000 \mathrm{~Hz}$ ) (Table 3). After surgery, ABG in $82.63 \%$ and $95.1 \%$ of patients reached to below 10 and $20 \mathrm{~dB}$, respectively. Complete deafness was reported in 3 patients. The best hearing outcomes were observed at $2000 \mathrm{~Hz}$ (Table 4).

A significant relationship between improvement in postsurgery $B C, A C$ and $A B G$ variables considering age, gender and involvement (unilateral or bilateral) was not observed in any of the frequencies $(p>0.05)$.

\section{Discussion}

In this study, most patient were in the $31-40$ age group, and females were more nemerous than males. The results of various studies indicate a higher incidence of disease in females $[1,5$, $6,10,13-17]$. In the present study, unilateral involvement was observed in $68.28 \%$ of cases, and in $60.29 \%$ of patients, surgery was performed on the right ear. In the study conducted by Saki et al., most of the patients had unilateral involvement, and only in $18.2 \%$ of cases was bilateral involvement observed [13]. In some studies, left ear involvement was reported more often $[16,18,19]$.

\section{Interpretation and generalizability}

In the present study, BC hearing improvement at different frequencies was $7.9 \mathrm{~dB}$. The audiological evaluation showed different results concerning post-surgery BC. In some studies, constant $B C$ thresholds were reported, while different degrees of progressive sensorineural hearing loss were shown in other studies. Mahafza et al. reported significant mean differences in pre- and post-surgery $\mathrm{BC}$ (hearing improvement) at $500-4000 \mathrm{~Hz}$ frequencies, which was $3.1 \mathrm{~dB}$ [16]. Redfors and Möller showed that post-surgery $B C$ was significantly improved, which equaled $6 \mathrm{~dB}[20]$. These findings are consistent with our results. Bernardo et al. showed a significant improvement in post-surgery $B C$ at all frequencies except $4000 \mathrm{~Hz}$, and mean improvement at all frequencies was $4.7 \mathrm{~dB}[6]$. On the other hand, in all audiometry conducted by Nair et al. [9], Hossain et al. [10] and Quaranta et al. [21], there was no significant change in $B C$ rates observed at the mentioned frequencies. These results are not consistent with the findings of our study.

In the study by Dankuc et al., pre- and post-mean BC at frequencies of 500, 1000 and $4000 \mathrm{~Hz}$ was not statistically significant, and it was concluded that the surgery had no effect on
$B C$ at the mentioned frequencies. However, at the $2000 \mathrm{~Hz}$ frequency, a significant difference between pre- and post-surgery $\mathrm{BC}$ was observed, and the means of $\mathrm{BC}$ were 35.75 and 31.97 , respectively [22]. The significant decrease in the $B C$ threshold at the $2000 \mathrm{~Hz}$ frequency led to a reduction in ossicles fluctuations in otosclerosis and internal stimulation problems, especially at a frequency of $2000 \mathrm{~Hz}$ [22]. In the present study, the highest rate of improvement in $\mathrm{BC}$ was observed at a frequency of 2000 $\mathrm{Hz}$, which is attributed to Carhart's notch phenomenon.

A worse BC threshold in the short term after surgery was reported by Tange and Grolman, which may be caused by cochlear trauma. However, this did not lead to weaker results [23].

The aim of otosclerosis surgery was improvement of $A C$ and ABG closure. Therefore, one of the main evaluation factors in stapedotomy surgery is AC threshold improvement [16]. In the present study, $A C$ hearing improvement at different frequencies was $29.9 \mathrm{~dB}$, which is undoubtedly good and is consistent with the results of other similar studies $[10,15,16]$. In our study, the highest pre- and post-surgery differences were observed at low frequencies ( 500 and $1000 \mathrm{~Hz}$ ).

The mean difference in pre- and post-surgery AC (hearing improvement) in the studies conducted by Hossain et al. [10], Mahafza et al. [16] and Dankuc et al. [22] were 23.58, 24.2 and 18.67 , respectively, which was more significant at low frequencies. These results suggest the effectiveness of otosclerosis treatment, especially at low frequencies, which is consistent with our results. The biggest improvement in AC threshold was observed at low frequencies [6]. Overall, the short-term results of the post-surgery AC were excellent in all research. For example, in the study by Kolo and Ramalingam [3], the mean difference between pre- and post-surgery $A C$ at the mentioned frequencies was $21.48 \mathrm{~dB}$. This threshold was 21.58 in study of Nair et al. [9].

In this study, we showed that the differences between preand post-surgery $A B G$ at all frequencies was statistically significant, with more differences observed at low frequencies $(500$, $1000 \mathrm{~Hz}$ ). The benefits of surgery include reduction or closure of $A B G$ in post-surgery PTA (short term \& long term) and hearing improvement, which was reported in several studies [6, 24]. Baradaranfar et al. [25] showed that the mean ABG at frequencies of 500-4000 dB decreased from 41.2 to $12.4 \mathrm{~dB}$ three months after surgery. In the study of Dankuc et al., the mean differences of pre- and post-surgery ABG at all frequencies was significant and equal to 19.92 (from 27.12 to $7.5 \mathrm{~dB}$ post-surgery) [22]. In the study conducted by Kolo and Ramalingam significant improvement in hearing after the first surgery was observed, and the mean differences of pre- and post-surgery ABG at frequencies of $0.5,1,2$ and $4 \mathrm{~Hz}$ were significantly decreased 
(from 43.14 to $19.17 \mathrm{~dB}$ ). Better post-operative hearing results at lower frequencies can be due to the fact that higher frequencies are usually more affected by the disease process [3]. Our results showed significant improvement in hearing, especially at low frequencies, which is consistent with previous studies.

In the present study, the post-operative $A B G$ threshold in $83 \%$ of cases reached below $10 \mathrm{~dB}$. The incidence of complete deafness after primary stapes bone surgery in this study was lower than other studies $(0.4$ to $3 \%)[11,16,19]$. In the study by Hossain et al., ABG below $10 \mathrm{~dB}$ and complete deafness was $84 \%$ and $2 \%$, respectively [10]. Sensorineural hearing loss (SNHL) in the study conducted by Nair et al. [9] and Vincent et al. [17] was $1 \%$ and $0.7 \%$, respectively.

Good surgical results ( $A B G \leq 10 \mathrm{~dB}$ ) were below $80 \%$ in some studies [14-16, 19]. In the study of Saki et al. [13], ABG below 10 , between $10-20$, above 30 and complete deafness was $63.9,29.9,2.5$ and 1\%, respectively. Bagherian [2015] showed a significant decrease in the mean difference between pre- and post-operative $A B G$ following otosclerosis surgery [18]. Dankuc et al. showed that an ABG threshold below $20 \mathrm{~dB}$ and $10 \mathrm{~dB}$ was $97 \%$ and $70 \%$, respectively [22]. In general, good post-operative auditory results have been reported in several studies; however, some differences in the auditory results of different studies can be related to the size of the sample examined, the size and type of prosthesis, as well as the severity of the disease [26], but these factors were not taken into consideration in this study.

Differences in the results can be attributed to sampling size and the population studied, the severity of the disease, or even the surgical technique, and the expertise and experience of the surgeon.

\section{Conclusions}

An improvement in hearing regarding a decrease in $A C$, $B C$ and $A B G$ showed that in $95 \%$, the $A B G$ threshold reached below $20 \mathrm{~dB}$, which indicates successful surgery results in the short term (mean follow-up 3.27 months). Therefore, primary stapedotomy surgery in patients with otosclerosis is effective in short-term improvement in adults. Further multi-centered prospective studies with a larger sample size are recommended under standard conditions and with a long-term follow-up period.

Acknowledgments. This study was the result of the dissertation thesis registered in Ahvaz Jundishapur University of Medical Sciences (AJUMS), Ahvaz, Iran and financially supported by the Vice-Chancellor for Research of the AJUMS and Hearing Research Center, AJUMS, Ahvaz, Iran (Registration number: HRC-9680).

Source of funding: This work was funded by the University's Vice-Chancellor for Research and Hearing Research Center. Conflicts of interest: The authors declare no conflicts of interest.

\section{References}

1. Modzelewska B, Samluk A, Wałejko $t$, et al. Influence of risky and protective behaviors connected with listening to music on hearing loss and the noise induced threshold shift among students of the Medical University of Bialystok. Fam Med Prim Care Rev 2017; 19(1): 44-48, doi: 10.5114/fmpcr.2017.65090.

2. Gil GLM, Palau EM, Jurado FJA, et al. Stapedotomy outcomes in the treatment of otosclerosis: our experience. Acta Otorrinolaringol Esp 2008; 59(9): 448-454.

3. Kolo ES, Ramalingam R. Hearing results in adults after stapedotomy. Niger Med J 2013; 54(4): 236-239.

4. House WJ, Cunningham DC. Otosclerosis. In: Cumming CW, Flint PW, Harker LA, et al., eds. Cummings otolaryngology head and neck surgery. 5th ed. Philadelphia: Elsevier Mosby; 2010: 1887-2035.

5. Markou K, Goudakos J. An overview of the etiology of otosclerosis. Eur Arch Otorhinolaryngol 2009; 266(1): 25-35.

6. Bernardo MT, Dias J, Ribeiro D, et al. Long term outcome of otosclerosis surgery. Braz J Otorhinolaryngol 2012; 78(4): 115-119.

7. Bayat A, Saki N, Nikakhlagh S, et al. Ossicular chain defects in adults with chronic otitis media. Int Tinnitus J 2019; 23: 6-9.

8. Tange RA, Grolman W. Late postoperative hearing results after stapedotomy. Int Adv Otol 2009; 5: 323-326.

9. Nair G, Pradhananga RB, Raghunandhan S, et al. Audiological outcomes of stapedotomy: our experience. SAS J Surg 2016; 2(5): 209-213.

10. Hossain MD, Rafiquzzaman M, Ahamed NU, et al. Surgical findings \& audiological outcomes of stapedotomy in patients with otosclerosis. Bangladesh J Otorhinolaryngol 2014; 20(2): 87-92.

11. Kileny RP, Zwolan AT. Otosclerosis. In: Cumming CW, Flint PW, Harker LA, et al., eds. Cummings otolaryngology head and neck surgery. 5th ed. Philadelphia: Elsevier Mosby; 2010: 1887-1903.

12. Calmels MN, Viana C, Wanna G, et al. Very far-advanced otosclerosis: stapedotomy or cochlear implantation. Acta Otolaryngol 2007; 127: 574-578.

13. Saki N, Nikakhlagh S, Hekmatshoar M, et al. Evaluation of hearing results in otosclerotic patients after stapedectomy. Iran J Otorhinolaryngol 2011; 4(23): 127-133.

14. Tange RA, Grolman W. Late postoperative hearing results after stapedotomy. Int Adv Otol 2009; 5(3): 323-326.

15. Simoncelli C, Ricci G, Trabalzini F, et al. Stapes surgery: a review of 515 operations performed from 1988 to 2002. Mediterr J Otol 2005; 1: $1-7$.

16. Mahafza T, AL-Layla A, Tawalbeh M, et al. Surgical treatment of otosclerosis: eight years' experience at the Jordan University Hospital. Iran J Otorhinolaryngol 2013; 25(4); 233-238.

17. Vincent R, Sperling NM, Oates J, et al. Surgical findings and long-term hearing results in 3,050 stapedotomies for primary otosclerosis: a prospectve study with the otology-neurotology database. Otol Neurotol 2006; 27(8 Suppl. 2): 25-47.

18. Bagherian Z. Evaluation of hearing outcomes following surgery in patients with otosclerosis referred to Tehran Valiasr hospital between 2006-2013 [general physician's thesis]. Teheran: Tehran University of Medical Sciences; 2015 (In Persian).

19. Vinicius AF, Celso GB, Roberto ESG, et al. Surgical treatment of otosclerosis in medical residency training. Rev Bras Otorrinolaringol 2006; 72(6): 38-42.

20. Redfors YD, Möller C. Otosclerosis: thirty-year follow-up after surgery. Ann Otol Rhinol Laryngol 2011; 120(9): 608-614.

21. Quaranta N, Besozzi G, Fallacara AR, et al. Air and conduction change after stapedotomy and partial stapedectomy for otosclerosis. Otolaryngol Head Neck Surg 2005; 133: 116-120.

22. Dankuc D, Pejakoviv N, Komazec Z, et al. Functional hearing results in patients with otosclerosis before and after stapedotomy. Med Pregl 2012; 1-2: 54-58.

23. Tange RA, Grolman W. Late postoperative hearing results after stapedotomy. Int Adv Otol 2009; 5(3): 323-326. 
24. Karhuketo TS, Lundmark J, Vanhatalo J, et al. Stapes surgery: a 32-year follow-up. ORL J Otorhinolaryngol Relat Spec 2007; 69(5): 322-326.

25. Baradaranfar M, Karimi G, Molasadeghi A, et al. assessment of surgical success rate and acoustic tests findings in patients with otosclerosis. JSSU 2010; 18(3): 256-262 (In Persian).

26. Mangham CA Jr. Titanium CliP piston versus platinum-ribbon Teflon piston: piston and fenestra size affect air-bone gap. Otol Neurotol 2008; 29(1): 8-12.

27. Lippy WH, Berenholz LP. Primary stapedectomy: the surgery. Ear Nose Throat J 2008; 87(12): 678-680.

Tables: 4

Figures: 1

References: 27

Received: 3.08.2018

Reviewed: 10.08 .2018

Accepted: 26.04.2019

Address for correspondence:

Karimi Mehdi, MD, PhD

Student Research Committee

Ahvaz Jundishapur University of Medical Sciences

Ahvaz

Iran

Tel.: +989379217677

E-mail: omre_man61@yahoo.com 